\title{
Rancang Bangun Mesin Replika Penghasil Gas Vulkanik sebagai Studi Awal Monitoring Erupsi Gunung Berapi
}

\author{
Umi Salamah $^{(\mathrm{a}) *}$, Qonitatul Hidayah ${ }^{(\mathrm{b})}$ dan Damar Yoga Kusuma ${ }^{(\mathrm{c})}$ \\ Jurusan Fisika, Universitas Ahmad Dahlan, Yogyakarta, Indonesia, 55191 \\ Email : ${ }^{\left(a^{*}\right)}$ umi.salamah@fisika.uad.ac.id, ${ }^{(b)}$ qonitatul.h@fisika.uad.ac.id, ${ }^{(c)}$ damar.kusuma@fisika.uad.ac.id
}

Diterima (10 Desember 2020), Direvisi (30 Januari 2021)

\begin{abstract}
Monitoring of volcanic gas is very important because it can be an indicator of an eruption. The development of the volcanic gas detection system has limitations on the test system which is carried out in-situ (taking gas samples directly from the volcano's crater). Instrumentation for gas detection systems developed on a laboratory scale requires test samples for gases that resemble volcanic gases, especially those that come out before an eruption. Therefore we need a gas-producing machine as a representation of volcanic gases. This research has designed a gas-producing engine as a replica of volcanic gas. This machine is very supportive of the development of volcanic gas research on a laboratory scale because it has advantages because it is lighter, simpler construction, the machine construction process is cheaper and portable. The gas produced by the machine is tested using the Dragger X-am 7000. CO2, $\mathrm{H} 2 \mathrm{~S}, \mathrm{SO} 2$, and $\mathrm{CO}$. The results were obtained for 60 seconds of starting the engine, namely CH4 2.0\% LEL, CO2 1.6\% Vol, H2S 4.3 ppm, SO2 1.0 ppm, and CO 271 ppm.

Keywords: Engine Replicas, Gas Content, Volcanic Gas
\end{abstract}

\begin{abstract}
Abstrak. Monitoring gas vulkanik sangat penting untuk dilakukan karena dapat menjadi indikator terjadinya erupsi. Perkembangan sistem deteksi gas vulkanik mempunyai keterbatasan pada uji system dimana dilakukan secara in-situ yaitu dengan mengambil sampel gas langsung pada kawah gunung berapi. Instrumentasi sistem deteksi gas yang dikembangkan pada skala labroratorium membutuhkan sampel uji gas yang menyerupai gas gunung berapi terutama yang keluar menjelang erupsi. Oleh sebab itu diperlukan mesin penghasil gas sebagai representasi gas vulkanik. Pada penelitian ini telah merancang bangun mesin penghasil gas sebagai replika gas vulkanik. Mesin ini sangat mendukung dalam pengembangan penelitian gas vulkanik pada skala laboratorium karena memiliki keunggulan karena lebih ringan, konstruksi sederhana, proses konstruksi mesin yang lebih murah dan portableGas yang dihasilkan oleh mesin tersebut diuji dengan menggunakan Dragger X-am 7000. Dari hasil pengujian diperoleh gas $\mathrm{CH}_{4}, \mathrm{CO}_{2}, \mathrm{H}_{2} \mathrm{~S}, \mathrm{SO}_{2}$, dan $\mathrm{CO}$. Hasil didapatkan selama 60 detik menyalakan mesin yaitu CH4 2,0 \%LEL, $\mathrm{CO}_{2} 1,6 \% \mathrm{Vol}, \mathrm{H}_{2} \mathrm{~S} 4,3 \mathrm{ppm}, \mathrm{SO}_{2} 1,0 \mathrm{ppm}$, dan $\mathrm{CO} 271 \mathrm{ppm}$.
\end{abstract}

Kata kunci: Gas vulkanik, Kadar Gas, Replika Mesin

\section{PENDAHULUAN}

Indonesia merupakan salah satu negara yang memiliki jumlah gunung berapi terbesar ketiga di dunia, beberapa gunung api tersebut adalah gunung api aktif. Hal ini menempatkan Indonesia menjadi wilayah rawan bencana dari aktivitas gunung api. Pada sisi lain, keberadaan gunung api di Indonesia merupakan objek penelitian yang memberikan peluang besar dalam kajian kegunungapian khususnya pengembangan instrumentasi untuk monitoring vulkanik. Sistem monitoring aktivitas vulkanik gunung berapi dapat meminimalisir korban jiwa pada peristiwa erupsi. Salah satu parameter yang digunakan dalam monitoring aktivitas vulkanik adalah keluarnya beracun. Gas beracun ini, dapat 
berupa gas $\mathrm{CO}, \mathrm{CO}_{2}, \mathrm{HCN}, \mathrm{H}_{2} \mathrm{~S}, \mathrm{SO}_{2}$, dll [1]. Sebagai contoh, adalah erupsi Merapi pada tahun 2010, terjadi peningkatan keluarnya gas vulkanik yang signifikan sebelum terjadinya erupsi [2]. Oleh sebab itu, monitoring gas gunung berapi sangatlah penting dalam pengembangan allow warning system terjadi erupsi sehingga dapat meminimalisir bencana.

Sistem deteksi gas vulkanik telah dikembangkan dengan beragam teknologi antara lain spektroskopi [3]-[6], elektrokimia [7], [8] dan teknologi Light Detection and Ranging (Lidar) [9]-[12]. Dalam penelitian rancang bangun sistem deteksi tersebut, pengujian biasanya dilakukan secara in-situ yaitu mengambil gas pada kawah gunung berapi. Hal tersebut menyebabkan pengujian tidak efektif dan memakan waktu lama. Di samping itu, untuk mengambil sampel gas dari kawah gunung berapi membutuhkan banyak peralatan dan juga resiko terhadap peneliti karena kontak langsung dengan gas beracun. Oleh sebab itu, dalam pengembangan metode dan teknologi instrumentasi pemantauan gas gunung berapi yang dilakukan dalam skala laboratorium sangat dibutuhkan replika sumber gas gunung berapi. Penelitian ini merancang bangun mesin penghasil gas dengan pemanfaatan prinsip kerja mesin 2 tak untuk menghasilkan gas replika gas vulkanik. Gas hasil pembakaran dari mesin ini antara lain $\mathrm{CH}_{4}, \mathrm{CO}_{2}, \mathrm{H}_{2} \mathrm{~S}, \mathrm{SO}_{2}$, dan $\mathrm{CO}$. Kadar gas tersebut kemudian diukur dengan menggunakan sensor gas Dragger X-am 7000 .

\section{METODE PENELITIAN}

Studi awal penelitian ini, memanfaatkan mesin 2 tak sebagai sumber penghasil gas berbahaya. mesin 2 tak terdiri dari blok silinder, kepala silinder, piston, batang piston, poros engkol, intake port, exhaust port, transfer port dan busi (spark plug). Gas hasil pembakaran bahan bakar dan udara

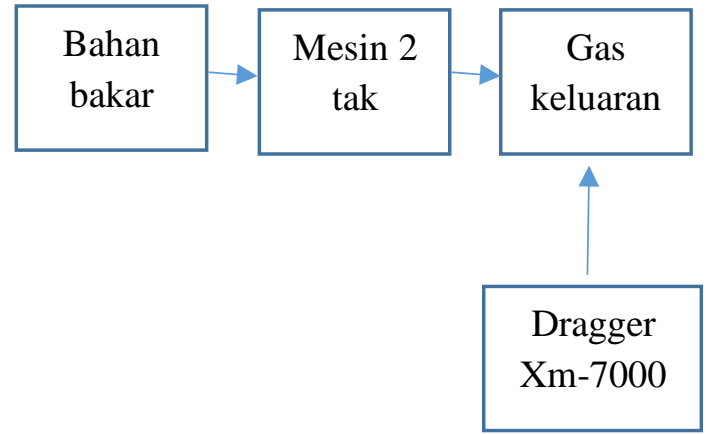

Gambar 1. Diagram blok pengambilan data

yang terjadi di dalam ruang pembakaran akan dideteksi dengan menggunakan sensor gas Dragger X-am 7000. Adapun diagram blok pengambilan data ditunjukan pada Gambar 1.

\section{HASIL DAN PEMBAHASAN}

Penelitian ini merancang sistem deteksi $\mathrm{CO}_{2}$ dalam skala laboratorium. Sumber gas $\mathrm{CO}_{2}$ menggunakan replika mesin 2 tak seperti pada Gambar 2. Kelebihan mesin 2 tak adalah lebih ringan, konstruksinya sederhana, dan proses konstruksi mesin yang lebih murah. Pemanfaatan proses dua langkah piston pada saat pembakaran bahan bakar dan udara di dalam ruang pembakaran, sehingga menghasilkan gas buang yang akan dideteksi. Gas yang dikeluarkan oleh mesin ini diuji dengan menggunakan sensor gas Dragger X-am 7000 seperti Gambar 3.

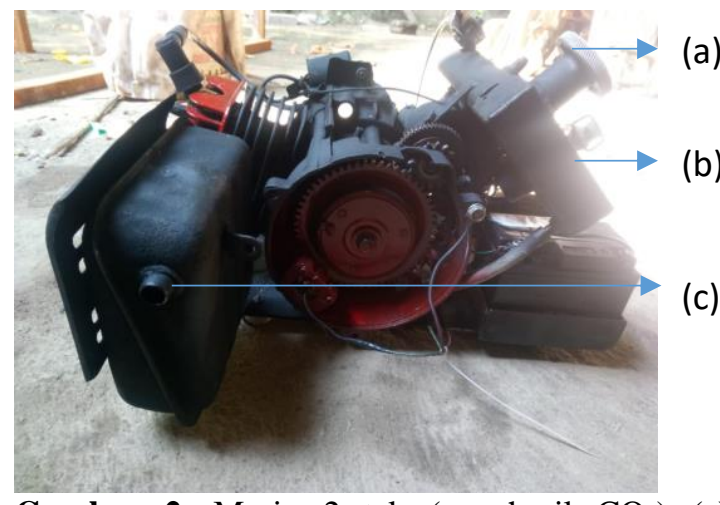

Gambar 2. Mesin 2 tak (penghasil $\mathrm{CO}_{2}$ ) (a) pengisian bahan bakar (b) starting mesin (c) pipa keluar gas 


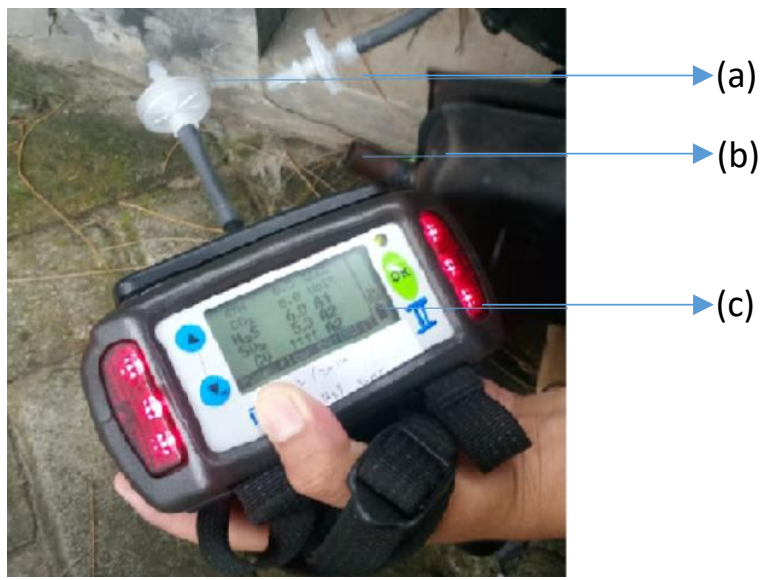

Gambar 3. Sensor gas Dragger X-am 7000 (a) selang/pipa input gas (b) sumber gas (c) layar deteksi gas beracun

Dragger X-am 7000 merupakan alat untuk mengukur kadar gas-gas Gunung Merapi secara in-situ atau kontak yaitu dengan memasukan gas masuk ke dalam tabung vakum yang terdapat pada alat tersebut. Gas-gas yang dideteksi antara lain $\mathrm{CH}_{4}, \mathrm{CO}_{2}, \mathrm{H}_{2} \mathrm{~S}, \mathrm{SO}_{2}$ dan $\mathrm{CO}$. Inilah yang menyebabkan sensor gas Dragger $\mathrm{X}$-am 7000 menjadi tidak efektif untuk monitoring aktivitas vulkanik gunung berapi. Dalam pengujian awal tersebut, mesin penghasil gas dinyalakan selama 60 detik kemudian direkam nilai dari masing-masing gas yang dihasilkan. Adapun Hasil yang diperoleh, ditunjukan pada Tabel 1.

Seperti yang ditunjukkan pada Tabel 1, mesin penghasil gas yang dirancang bangun menghasilkan beberapa gas buangan hasil pencampuran bahan bakar dan udara yaitu $\mathrm{CH} 4$ 2,0 \%LEL, $\mathrm{CO}_{2}$ 1,6 \% Vol, $\mathrm{H}_{2} \mathrm{~S} 4,3$ ppm, $\mathrm{SO}_{2} 1,0$ ppm, dan $\mathrm{CO} 271$ ppm Gasgas lainnya yang terdeteksi merupakan

Tabel 1. Hasil Pengujian awal mesin 2 tak

\begin{tabular}{lll}
\hline Jenis Gas & Kadar & Satuan \\
\hline $\mathrm{CH}_{4}$ & 2,0 & \% LEL \\
$\mathrm{CO}_{2}$ & 1,6 & Vol \% \\
$\mathrm{H}_{2} \mathrm{~S}$ & 4,3 & ppm \\
$\mathrm{SO}_{2}$ & 1,0 & ppm \\
$\mathrm{CO}$ & 271 & ppm \\
\hline
\end{tabular}

representasi beberapa gas yang keluar dari gunung berapi ketika mengalami aktivitas vulkanik. Gas $\mathrm{CO}_{2}$ yang terdeteksi sebesar 1,6 Vol\%, jika dikonversi ke dalam ppm (part per million) nilainya adalah 16.000 ppm. Nilai tersebut sudah melebihi ambang normal di udara bebas sebesar $0,5 \%$ vol atau 5000 ppm. Kadar gas CO yang berbahaya bagi tubuh adalah yang melebihi $50 \mathrm{ppm}$ [13], yaitu 271 ppm. Ketika manusia terpapar gas $\mathrm{CO}$, konsentrasi gas tersebut dalam $\mathrm{Hb}$ darah bisa mencapai $20-30 \%$. Hal ini dapat menyebabkan manusia yang terpapar gas $\mathrm{CO}$ akan mengalami sakit kepala sedang, berdenyut-denyut, dahi, wajah merah dan mual [14]. Semakin lama waktu paparan yang dihasilkan oleh mesin 2 tak, kadar gas $\mathrm{CO}_{2}$ dan gas $\mathrm{CO}$ yang dihasilkan menjadi lebih besar. $\mathrm{SO}_{2}$ yang merupakan salah gas yang dikeluarkan oleh setiap gunung berapi. Pada kasus khusus, gunung berapi yang tergolong sedikit mengeluarkan gas seperti Gunung Merapi $\mathrm{SO}_{2}$ dipantau secara intensif.

Setiap gunung berapi mempunyai ciri khas gas vulkanik masing-masing. Pada erupsi Gunung Merapi 2010 gas yang dikeluarkan antara lain $\mathrm{N}_{2}, \mathrm{CH}_{4}, \mathrm{CO}, \mathrm{CO}_{2}$, $\mathrm{H}_{2} \mathrm{~S}, \mathrm{HCL}, \mathrm{SO}_{2}, \mathrm{NH}_{3}$ dan $\mathrm{H}_{2} \mathrm{O}$ [15-16]. Diantara gas-gas tersebut yang mengalami peningkatan signifikan menjelang erupsi antara lain $\mathrm{CO}_{2}, \mathrm{SO}_{2}, \mathrm{H}_{2} \mathrm{~S}, \mathrm{~N}_{2}$. Sedangkan pada Gunung Kelut gas vulkanik yang dikeluarkan menjelang erupsi didominasi oleh $\mathrm{CO}_{2}$ dan $\mathrm{H}_{2} \mathrm{O}$ [17]. Pada kasus erupsi Gunung Fuji, menjelang erupsi peningkatan gas yang terjadi adalah gas $\mathrm{CO}_{2}$ [18]. Dari ketiga gunung berapi tersebut, jenis gas yang dikeluarkan menjelang erupsi merupakan jenis gas yang sama dengan gas yang dihasilkan oleh mesin penghasil gas yang dirancang bangun kecuali $\mathrm{N}_{2}$. Oleh sebab itu, mesin yang dirancang bangun dapat menjadi representasi gas vulkanik sebagai sampel uji pengembangan instrumentasi deteksi gas vulkanik pada skala laboratorium. 


\section{KESIMPULAN}

Replika mesin 2 tak telah berhasil menghasilkan gas beracun seperti identifikasi dalam aktivitas vulkanik pada gunung berapi. Dalam waktu 60 detik, gas yang dihasilkan dari pembuangan replica mesin 2 tak CH4 2,0 \%LEL, $\mathrm{CO}_{2} 1,6 \% \mathrm{Vol}$, $\mathrm{H}_{2} \mathrm{~S} 4,3$ ppm, $\mathrm{SO}_{2} 1,0 \mathrm{ppm}$, dan $\mathrm{CO} 271$ ppm. Batas ini sudah melebihi ambang udara yang diperbolehkan. Semakin lama waktu paparan yang dihasilkan oleh mesin 2 tak, kadar gas $\mathrm{CO}_{2}$ dan gas $\mathrm{CO}$ yang dihasilkan juga semakin besar.

\section{UCAPAN TERIMAKASIH}

Ucapan terimakasih kepada Kementrian Riset dan Teknologi/ Badan Riset dan Inovasi Nasional, selaku pemberi dana penelitian dengan kontrak Nomor : 26/INS-1/PPK/E4/2020

\section{DAFTAR PUSTAKA}

[1] Subono, A. Hidayat, dan A. Afandi, "Rancang Bangun Pendeteksi Gas CO dan H 2 S sebagai Early Warning System ( EWS ) di Kawah Gunung Ijen", J. Ilm. Flash, vol. 4, no. 2, pp. 105-112, 2018.

[2] T. R. Walter, R. Wang, M. Zimmer, H. Grosser, B. Lühr, dan A. Ratdomopurbo, "Volcanic Activity Influenced by Tectonic Earthquakes: Static and Dynamic Stress Triggering At Mt. Merapi", Geophys. Res. Lett., vol. 34 , no. 5, pp. 1-5, 2007, doi: 10.1029/2006GL028710.

[3] H. Humaida, "A Study on Carbon Isotope of Co 2 And Ch in Western Dieng Plateu by Gas Chromatography Isotope Ratio Mass Spectrometer (Gc-Irms )", Indones. J. Chem., vol. 5, no. 1, pp. 11-14, 2005, doi: https://doi.org/10.22146/ijc.21832.

[4] S. Gersen, van Essen, V., Visser, P.,
M. Ahmad, A. Mokhov, A. Sepman, Alberts, R., Douma, A. dan H. Levinsky, "Detection of H2S, So2 and $\mathrm{NO} 2$ in $\mathrm{CO} 2$ at Pressures Ranging from 1-40 bar by Using Broadband Absorption Spectroscopy in the UV/VIS Range", Energy Procedia, vol. 63, no. 2, pp. 25702582, 2014, doi: 10.1016/j.egypro. 2014.11.279.

[5] S. Inguaggiato, I. S. Diliberto, C. Federico, A. Paonita, dan F. Vita, "Review of the Evolution of Geochemical Monitoring, Networks and Methodologies Applied to the Volcanoes of the Aeolian Arc (Italy)", Earth-Science Rev., vol. 176, no. March 2017, pp. 241-276, 2018, doi: 10.1016/j.earscirev.2017.09.006.

[6] F. Quattrocchi, B. Cantucci, D. Cinti, G. Galli, L. Pizzino, A. Sciarra, dan N. Voltattorni, "Continuous/Discrete Geochemical Monitoring of $\mathrm{CO} 2$ Natural Analogues and of Diffuse Degassing Structures (DDS): Hints for $\mathrm{CO} 2$ Storage Sites Geochemical Monitoring Protocol", Energy Procedia, vol. 1, no. 1, pp. 21352142, 2009, doi: 10.1016/j.egypro. 2009.01.278.

[7] M. Shofar dan S. Suryono, "Sistem Telemetri Pemantau Gas Karbon Dioksida (Co2) Menggunakan Jaringan Wifi," Youngster Phys. J., vol. 3, no. 3, pp. 243-248, 2014.

[8] T. J. Roberts, "Electrochemical Sensing of Volcanic Gases", Chem. Geol., vol. 332-333, pp. 74-91, 2012, doi: 10.1016/j.chemgeo.2012.08.027.

[9] A. Gardi, R. Kapoor, dan R. Sabatini, "Detection of Volatile Organic Compound Emissions from Energy Distribution Network Leaks by Bistatic LIDAR," Energy Procedia, vol. 110, no. December 2016, pp. 396-401, 2017, doi: 10.1016/j.egypro.2017.03.159. 
[10] F. Gibert, P. H. Flamant, D. Bruneau, dan C. Loth, "Two-micrometer Heterodyne Differential Absorption Lidar Measurements of the Atmospheric CO 2 Mixing Ratio in the Boundary Layer", 2006.

[11] A. O. Langford, "Coordinated profiling of stratospheric intrusions and transported pollution by the Tropospheric Ozone Lidar Network (TOLNet) and NASA Alpha Jet experiment (AJAX): Observations and Comparison to HYSPLIT, RAQMS, and FLEXPART", Atmos. Environ., vol. 174, no. September 2017, pp. 1-14, 2018, doi: 10.1016/j.atmosenv.2017.11.031.

[12] Z. Qi, T. Zhang, G. Han, D. Li, X. Ma, dan W. Gong, "A Nonlinear Merging Method of Analog and Photon Signals For CO2 Detection in Lower Altitudes Using Differential Absorption Lidar," Opt. Commun., vol. 388 , no. November 2016, pp. 68 76, 2017, doi: 10.1016/j.optcom. 2016.11.071.

[13] J. Pramono, T. Susila, dan pono budi Mardjoko, "Perancangan Alat Telemetri Temperatur dan Gas Pada Gunung Berapi Secara Wireless", vol. 17, no. 1, pp. 88-103, 2015.

[14] A. Hidayat and Subono, "Rancang Bangun Sistem Monitoring Gas Beracun Kawah Ijen", Snitt, p. 41, 2018.

[15] S. J. Cronin, G. Lube, D. S. Dayudi, S. Sumarti, S. Subrandiyo, dan Surono, "Insights into the October-
November 2010 Gunung Merapi Eruption (Central Java, Indonesia) from the Stratigraphy, Volume and Characteristics of its Pyroclastic Deposits," J. Volcanol. Geotherm. Res., vol. 261, no. November 2010, pp. 244-259, 2013, doi: 10.1016/j.jvolgeores.2013.01.005.

[16] M. Surono, P. Jousset, J. Pallister, M. Boichu, M.F. Buongiorno, A. Budisantoso, C.F. Rodriguez, S. Andreastuti, F. Prata, D. Schneider, L. Clarisse, H. Humaida, S. Sumarti, C. Bignam, J. Griswold, S. Carn, C. Oppenheimere dan F. Lavigne, "The 2010 Explosive Eruption of Java' $\mathrm{s}$ Merapi volcano - a' 100-year' event To cite this version: HAL Id : insu$00723412, " 2012$.

[17] A. J. Jeffery, R. Gertisser, V.R. Troll, E.M. Jolis, B. Dahren, C. Harris, A.G. Tindle, K. Preece, B. O'Driscoll, H. Humaida dan J.P. Chadwick, "The Pre-Eruptive Magma Plumbing System of the 2007 - 2008 DomeForming Eruption of Kelut volcano, East Java, Indonesia," pp. 275-308, 2013, doi: 10.1007/s00410-0130875-4.

[18] K. Notsu, T. Mori, S. C. Do Vale, H. Kagi, and T. Ito, "Monitoring Quiescent Volcanoes by Diffuse CO2 degassing: Case study of Mt. Fuji, Japan," Pure Appl. Geophys., vol. 163, no. 4, pp. 825-835, 2006, doi: 10.1007/s00024-006-0051-0. 
Umi Salamah: Rancang Bangun Mesin Replika Penghasil Gas Vulkanik sebagai Studi Awal Monitoring Erupsi Gunung Berapi 